\title{
Investigations Concerning the Corrosion and Ultrasonic Cavitation Erosion of 316L Coatings Deposited HVOF on Nodular Cast Iron
}

\author{
ION-DRAGOS UTU, ION MITELEA, ILARE BORDEASU*, TRAIAN BENA \\ University Politehnica Timisoara, 2 Victoriei Sq., 300006 Timisoara, Romania
}

\begin{abstract}
Stainless steel 316L coating was high velocity oxygen fuel (HVOF) sprayed onto the surface of nodular cast iron in order to improve its surface properties in terms of corrosion and cavitation resistance. The cavitation resistance and corrosion behaviour of the nodular cast iron was investigated before and after coating deposition. The morphology and microstructure of the samples was analysed by optical and scanning electron microscopy (SEM) and X-ray diffraction technique (XRD). The cavitation measurements were carried out on a standard vibrator device. They have been correlated with the microhardness and surface roughness measurements. The corrosion evaluation was made by electrochemical tests. The results showed enhanced values in cavitation resistance of approx. 2.7 times and a decreasing of the corrosion rate for the coated cast iron.
\end{abstract}

Keywords: cavitation resistance, thermal sprayed coatings, corrosion behaviour, surface

Nodular castiron are materials with good machinability, castability, shock absorption, self-lubrication, and low price being widely used for manufacturing of complex shape components from automotive industry, metallurgy, marine machinery, etc. which can be subjected to mechanically vibration during exploitation [1, 2].

The main characteristic of nodular graphite cast iron is related to the more or less spherical shape of the graphite. As a result of this, the tendency to propagate the cracks is prevented and the conditions for obtaining satisfactory ductility and tenacity characteristics are created [3-5]. It is mentioned that the nodular graphite, whose surface in a given volume is minimal, affects to a lesser ratio the iron metal matrix compared to the lamellar graphite. Thus, it allows the use of $60 \div 80 \%$ of the tensile strength and 30 $\div 50 \%$ of the elongation and reduction in area of the base metallic mass. At the same time, the ratio $\mathrm{Rm} / \mathrm{HB}=0.26-$ 0.36 is much higher than of the lamellar graphite castiron, and $\mathrm{Rp} 0.2 / \mathrm{Rm} \approx 0.7$ is higher than for the casting steels [ 6 , 7].

However, for hydrodinamic severe operating conditions, obtained by direct measurements or simulation $[8,9]$, their performance and reliability may be limited due to various forms of wear, including cavitation erosion [10].

In order to enhance the cavitation erosion phenomenon many surface treatments including coating deposition [11]. HVOF process is a very well-known method used for coating deposition to reduce the effects of wear caused by abrasion, sliding, cavitational erosion and corrosion [1215].
The main objective of the present paper is to establish the surface characteristics in terms of cavitation resistance and corrosion behaviour of a nodular cast iron which was HVOF sprayed by a 316L stainless steel coating.

\section{Experimental part}

For investigations, as substrate material, it has been used a nodular cast iron EN-G] S-400-15 which has been subjected to stress relief annealing heat treatment at a temperature of $500 \pm 10^{\circ} \mathrm{C}$. The gas atomized powder (Amperit 377.065) having the chemical composition similar to AISI 316L stainless steel has been used for coating deposition using HVOF method. The particle size of the powder was $-30+10 \mu \mathrm{m}$. Before spraying, the substrate was sand blasted and cleaned with acetone in order to provide a good adherence of the coating.

The thermal spraying process was conducted on a SulzerMetco equipment which includes a control module, a DJ M 2700 spray gun mounted on a 6-axis movement robot and a powder feeder. As combustion gas a mixture of oxygen ( $430 \mathrm{~L} / \mathrm{min}$ ) and propane $(70 \mathrm{~L} / \mathrm{min})$ was used. Nitrogen was used as carrier gas. The deposition distance was kept constant at a value of $150 \mathrm{~mm}$. The thickness of the coatings was about $270 \mu \mathrm{m}$.

In order to determine the cavitation resistance of the samples a vibrating equipment with piezoceramic crystals was used [16]. The shape and the size of the cavitation samples is shown in figure 1 .

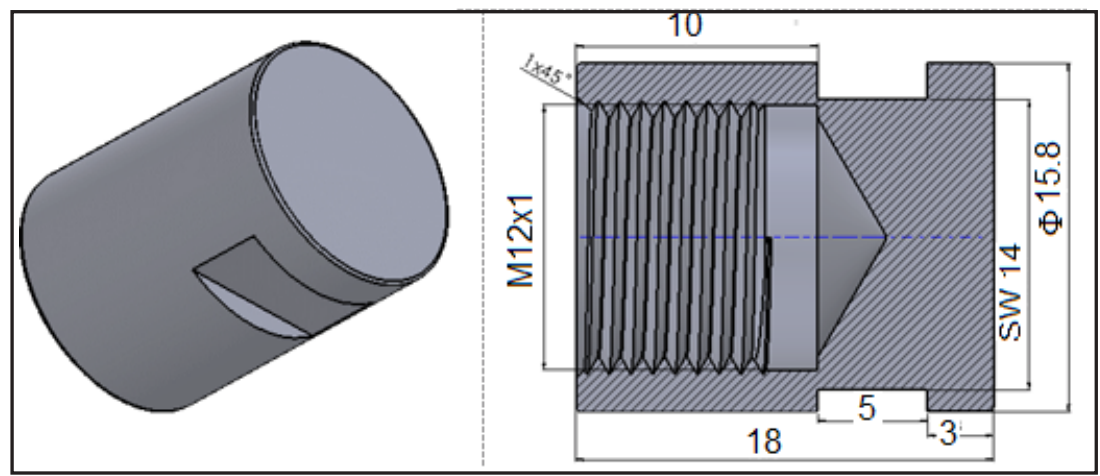

Fig.1.Geometry of samples tested at cavitation

*email: ilarica59@gmail.com 
The experiments were performed in drinking water (at a temperature of $22 \pm 1^{\circ} \mathrm{C}$ ) in strict accordance with international norms ASTM G32-2010 [17], and the laboratory custom [18]. The whole duration of a cavitation test was 165 min being divided in $\mathrm{i}=12$ periods of 5,10 and $15 \mathrm{~min}$.

After each testing period, the samples were weight being determined the material mass lost by cavitation erosion, respective the mean depth of erosion (MDE) and the related mean depth erosion rate (MDER); also, microhardness and eroded surface roughness measurements, macroscopic and microscopic examinations for characterizing the morphology of the transformations occurred in the surface layer eroded by cavitation and electrochemical corrosion tests were used to evaluate the characteristics of the investigated materials.

\section{Evaluation and interpretation of the experimental results} Micrographic analysis and X-Ray diffraction measurements

The microstructure of the nodular cast iron can be seen in figure 2. Analysing the image one can notice the presence of the graphite inclusions surrounded by the metallic matrix.

Figure 3 presents the cross-sectional laser scanning micrographs of the HVOF coated cast iron using stainless steel powders. One can observe a dense coating, without any cracks, showing a lamellar structure which is normally for a HVOF sprayed coating. There are no metallic continuity defects on the coating-substrate interface.

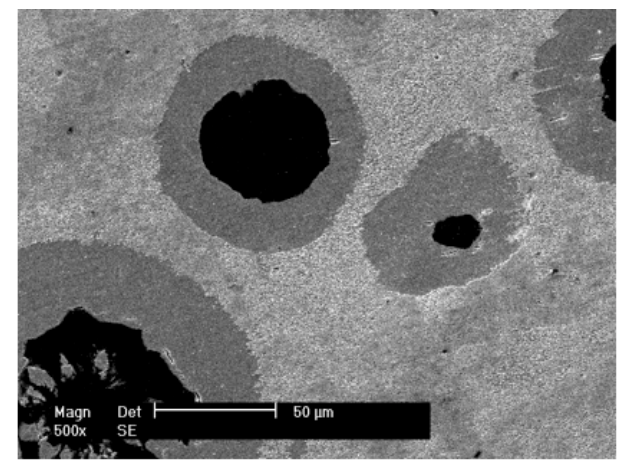

Fig. 2. Microstructure of nodular cast iron. Etching, NITAL 3\%
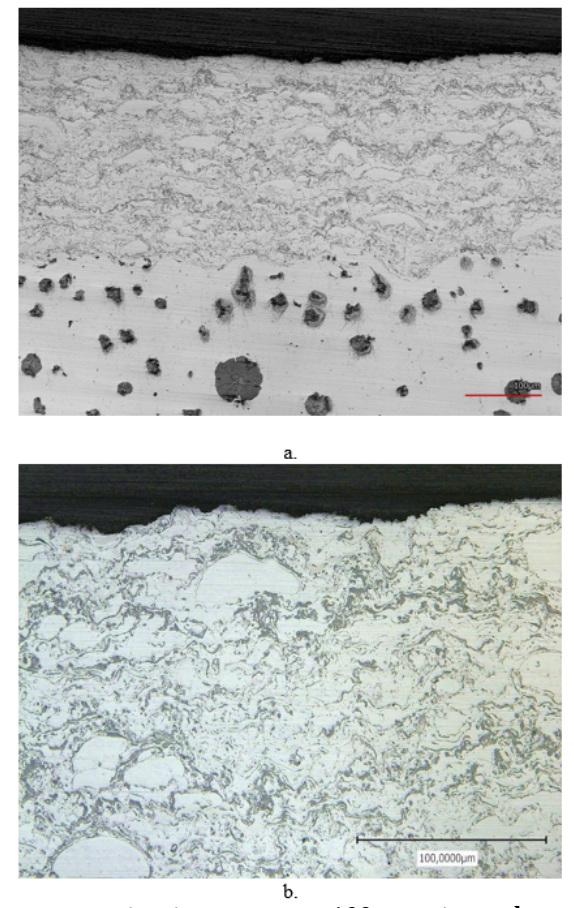

Fig.3. Laser scanning images: a -x 100, coating-substrate system; b $-x 200$, cross section of the deposited $316 \mathrm{~L}$ coating
The phase composition of the selected powders and of the HVOF deposited coatings was investigated by X-ray diffraction analysis (Philips X'Pert Diffractometer) using Cu-K $\alpha(\lambda=1.54 \AA)$ radiation. The measurements were carried out at room temperature, in 2 theta geometry, in the range $200-1000$, at a scanning rate of 10/ min. It was set up a voltage of $40 \mathrm{KV}$ with a current of $30 \mathrm{~mA}$. The crystallographic identification of the samples phases was performed using the JCPDS database.

The XRD patterns of the AISI $316 \mathrm{~L}$ stainless steel powder and the HVOF deposited coating are shown in Fig. $4 a$ and 4b. From their analysis it can be observed that the microstructure of both materials consists of austenite $(A)$ with small proportions ( $6-9 \%)$ of ferrite $\delta\left(F_{\delta}\right)$.

It is known that in order to provide a high resistance to hot cracking, the deposited metal must not be completely austenitic but have a structure consisting of austenite and a proportion of 4 - $12 \%$ ferrite $\delta$ [19-20].
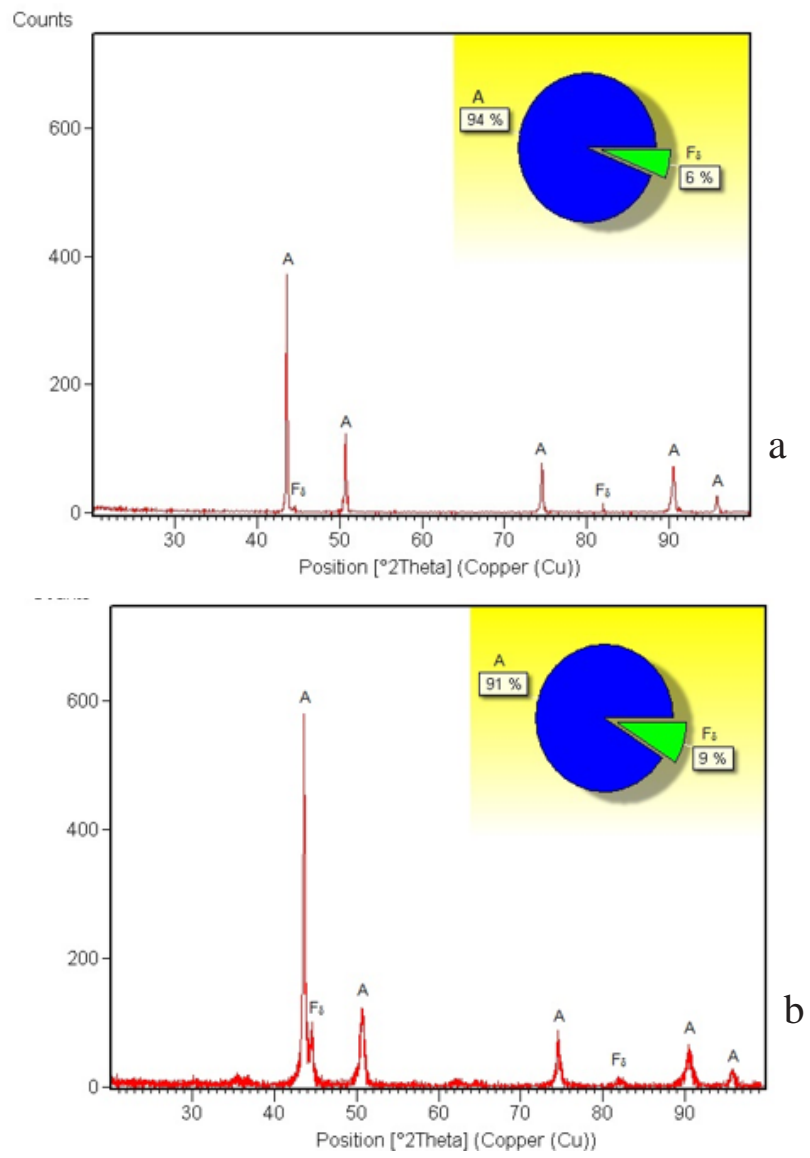

Fig. 4. XRD diffraction patterns: a. AISI 316L stainless steel powder, b. HVOF sprayed coating

\section{Hardness measurements}

The intensity of the microstructural changes produced in the coating-substrate system, shown in figure 3 , was evaluated by microhardness measurements, HV0.05. Microhardness values variation on the cross section of the coated samples is revealed in figure 5 .

The surface layer, having a fine and dense structure with a high density of crystalline lattice defects due to the workhardening effect, presents relatively high values of hardness ( $385 \pm 16 \mathrm{HV} 0.05$ ). This is a premise for improving the cavitation erosion resistance. In contrast, the substrate hardness is lower ( $255 \pm 10$ HV0.05), corresponding to the ferrite-pearlite microstructure of the base metallic mass of the cast iron. 


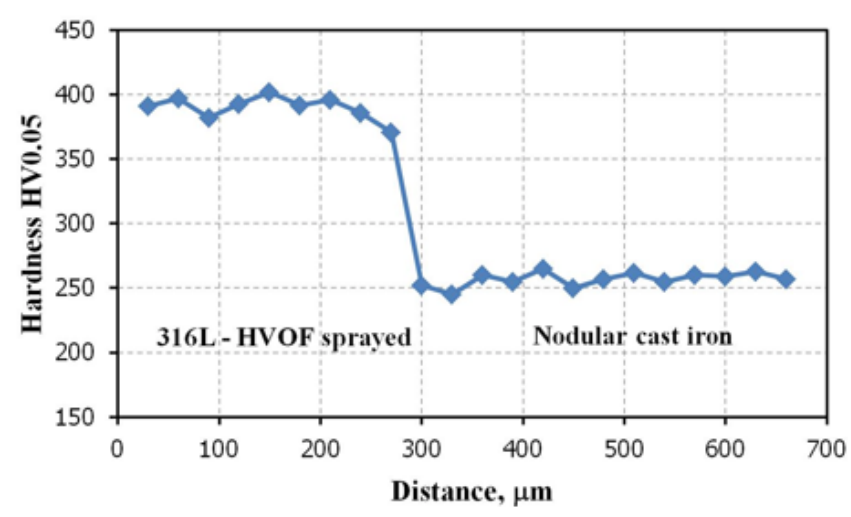

Fig. 5. Microhardness profile of the coated cast iron

\section{Cavitation curves}

The cavitation tests were carried out on two sets of three samples, one set being characteristic to the reference material (cast iron subjected to stress relief annealing heat treatment) and the other, to the HVOF sprayed coating using austenitic stainless steel powder.

By gravimetric measurements the cumulative average mass losses were determined and using these was further calculated the mean depth of erosion, $\mathrm{MDE}$, and the related mean depth erosion rate, MDER;

$$
\mathrm{MDE}_{\mathrm{i}}=\sum_{\mathrm{i}=1}^{12} \Delta \mathrm{MDE}_{\mathrm{i}}=\sum_{\mathrm{i}=1}^{12} \frac{4 \cdot \Delta \mathrm{M}_{\mathrm{i}}}{\rho \cdot \pi \cdot \mathrm{d}_{\mathrm{p}}^{2}}[\mathrm{~mm}]
$$

$$
\mathrm{MDER}_{\mathrm{i}}=\Delta \mathrm{MDE}_{\mathrm{i}} / \Delta \mathrm{t}_{\mathrm{i}}[\mathrm{mm} / \mathrm{min}]
$$

where:

\section{i -period testing;}

$\Delta \mathrm{Mi}$ - is material mass (in grams) lost by erosion during time i;

$$
\rho \text {-cast iron density, in grams } / \mathrm{mm} 3 \text {; }
$$

$\Delta$ ti -cavitation duration for period $\mathbf{i}(5,10$ or $15 \mathrm{~min}$ );

$\mathrm{dp}$-diameter of the sample surface, subjected to cavitation attack $(\mathrm{dp}=15.8 \mathrm{~mm})$;

$\triangle M D E i$-mean depth penetration value of cavitation erosion in the period of time $\Delta$ ti.;

MDERi -mean depth erosion rate value of cavitation in the period of time $\Delta$ ti..

Figures 6 and 7 show the variation curves of the two parameters that characterize the cavitation resistance according to the test duration.

It can be noticed that after the coating process, the values of the maximum erosion penetration depth, MDEmax. and erosion rate during the stabilization period, MDERs, are reduced by more than 2 times compared to the reference structural state (stress relief annealed cast iron). According to the international rules, the resistance to cavitation erosion is defined by the inverse of the erosion rate during the stabilization period, Rcav. $=1 /$ MDERs, so it results:

- uncoated cast iron - Rcav. $=1 / 0.48=2.08 \mathrm{~min} . / \mathrm{um}$

- coated cast iron - Rcav. $=1 / 0.18=5.55 \mathrm{~min} . / \mu \mathrm{m}$

Consequently, the proposed coating process favours an increase in cavitation resistance of approx. 2.7 times. The explanation for this improvement is based on the fine microstructure and the high hardness of the deposited coating.

\section{Surface topographyand microstructure of cavitation eroded coating}

After each testing period, the sample surfaces were macroscopically examined and photographed (fig. 9).

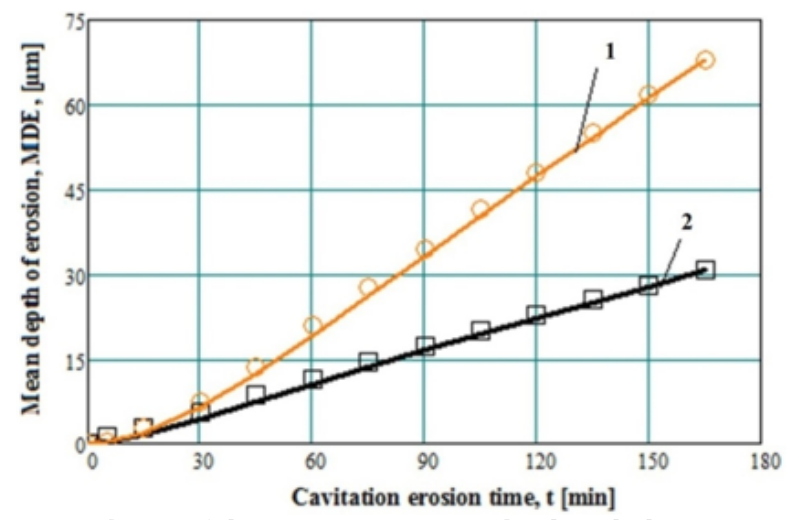

Fig.6. Evolution of the mean penetration depth with the cavitation attack duration: 1- uncoated surface; 2 - coated surface

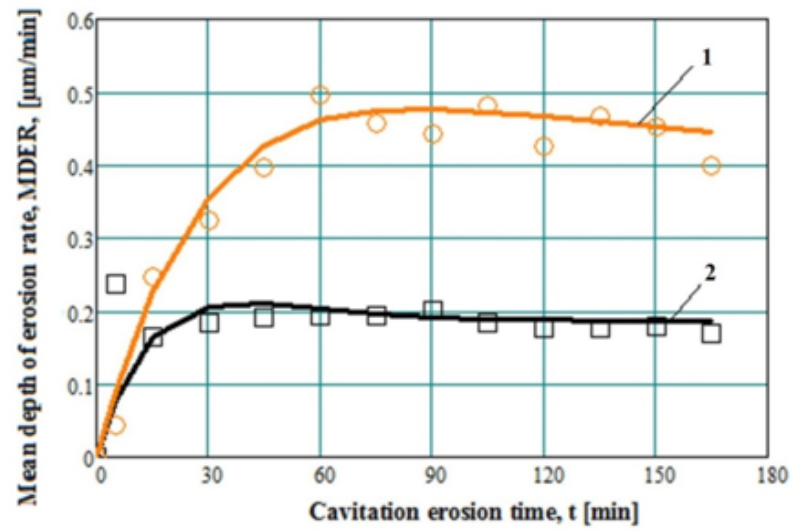

Fig.7. Evolution of the mean penetration depth of erosion rate with the cavitation attack duration: 1- uncoated surface; 2 - coated surface

The comparative analysis of eroded surfaces highlights that in the first $45 \mathrm{~min}$. of the cavitation attackat the uncoated cast iron and $165 \mathrm{~min}$. by the HVOF coated cast iron, it is not revelead a significant deterioration of their macrogeometry, phenomenon that can be explained by reduced material expulsion at the beginning of the wear process. At longer times of attack, there are some small material pinches that have an uniform distribution over the entire coated surface.

The investigations performed at the scanning electron microscope regarding the topography of cavitation tested surfaces for $165 \mathrm{~min}$. (fig. 8) confirms the improvement of cavitation erosion resistance by HVOF technique using austenitic stainless steel particles. Analysing the degree of surface damage for both types of specimens, different morphologies can be observed.

Thus, in the case of uncoated cast iron (fig. $9 a, b$ ) the cavitational attack is initiated at the interface between the graphite inclusions and the metal matrix. Beside the cracking phenomena a severe deformation occurs. There is also a graphite expulsion, which leads to the formation of deep cracks or craters with high stress concentrators. The degradation and the removal of the material is produced by fatigue break mechanism; at the bottom of the holes caused by the graphite separation, one can observe the presence of some micro tunnels (fig. 10) [19, 20].

The coated cast iron (fig. $9 \mathrm{c}$, d) has a more uniform material degradation; the eroded area shows no pinches, micro cracks or deep craters showing better cavitation behaviour than of the uncoated nodularcast iron.

The microstructure of the cross section eroded samples (fig. 11a) confirms the graphite expulsion during the cavitation attack and the presence of the micro-cracks 


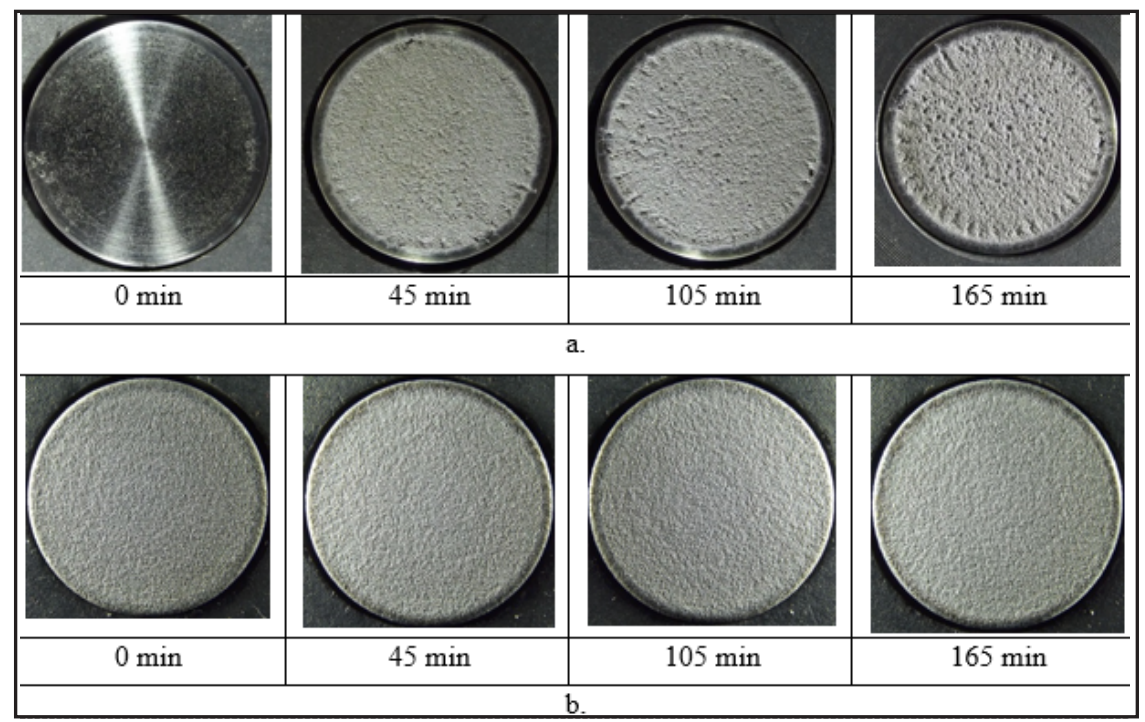

Fig.8. Macroscopic aspect of the cavitated surface: a. uncoated cast iron, b. coated cast iron
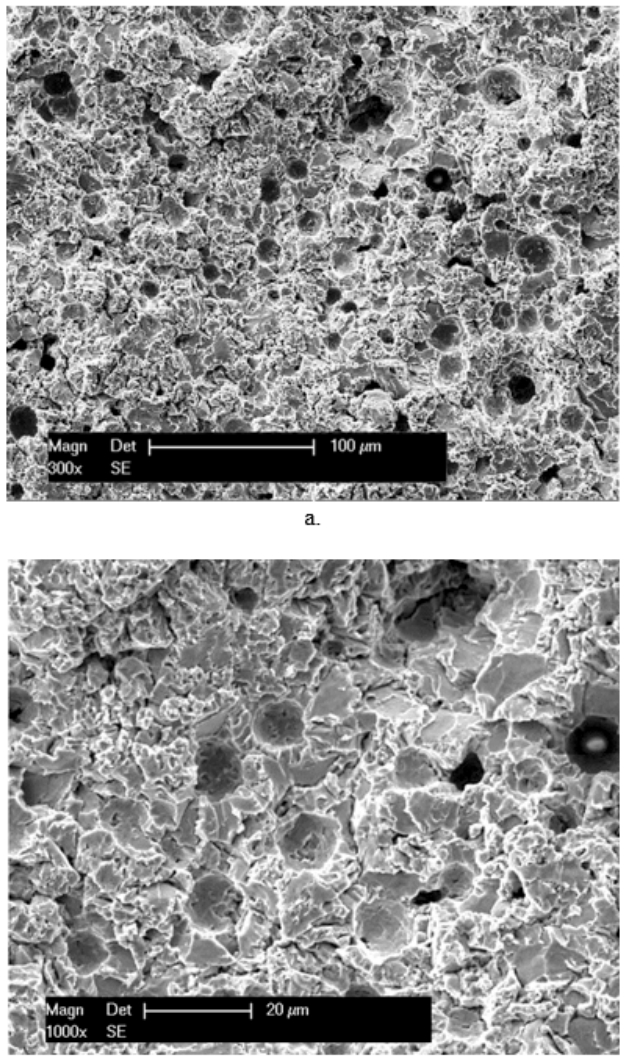
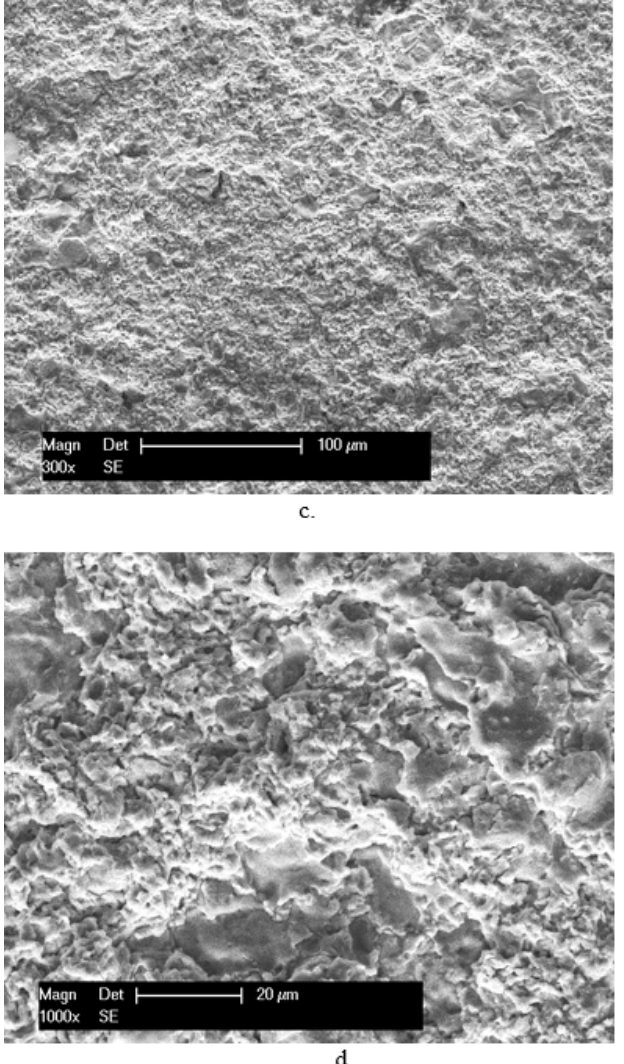

Fig.9. Morphologies of the eroded surfaces after the cavitation attack:

$a-x$ 300; b - x 1000, nodular cast iron (uncoated); c - x 300; $d-x$ 1000, 316L - HVOF sprayed (coated cast iron)

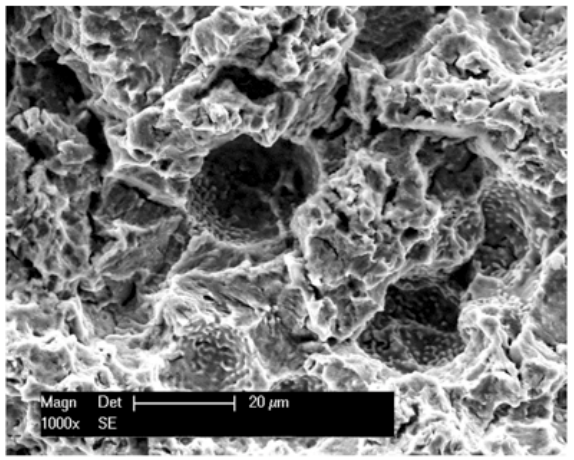

Fig. 10.x 1000 SEM image of a microtunnel
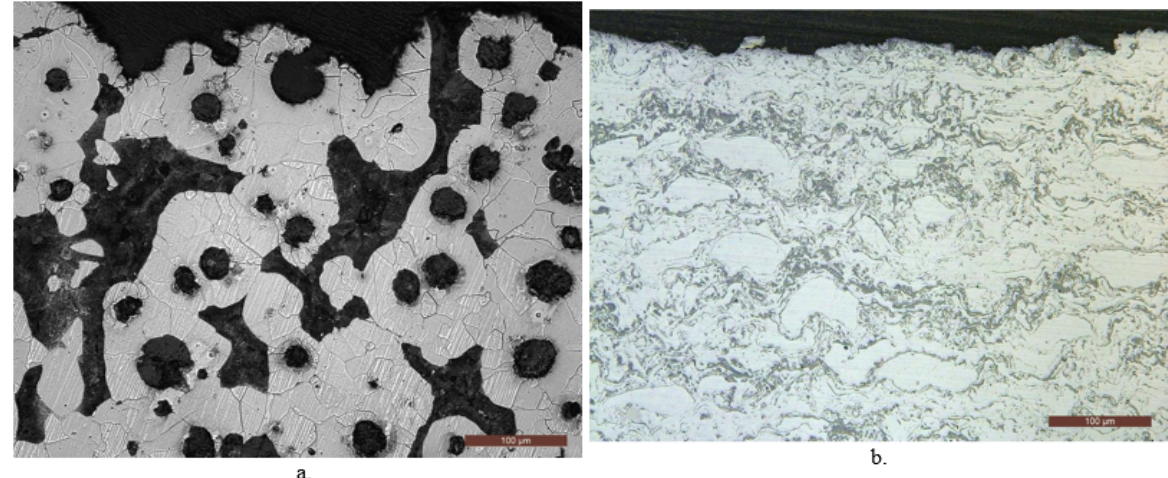

Fig.11. Microstructure of the upper area from the cross section of cavitation eroded surface: a - x 200, uncoated cast iron; b - x 200, coated cast iron 


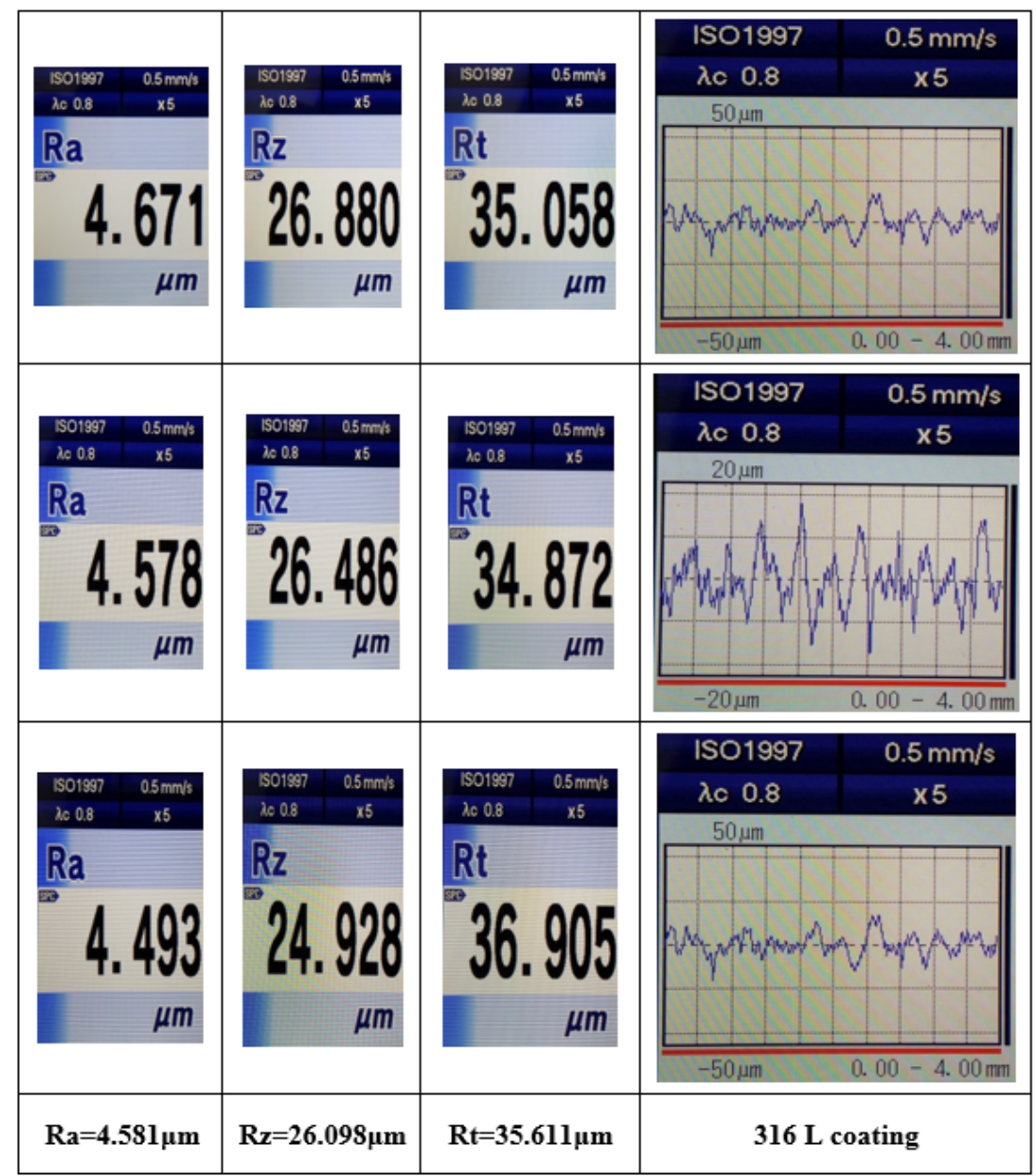

\begin{tabular}{|c|c|c|c|c|}
\hline Sample state & $\begin{array}{c}\mathrm{MDE}_{(165 \text { minutes })} \\
{[\mu \mathrm{m}]}\end{array}$ & $\mathrm{Ra}[\mu \mathrm{m}]$ & $\mathrm{Rz}[\mu \mathrm{m}]$ & Rt $[\mu \mathrm{m}]$ \\
\hline $\begin{array}{l}\text { Uncoated cast iron } \\
\text { (stress relief annealed) }\end{array}$ & 67.802 & 14.306 & 74.01 & 101.097 \\
\hline $\begin{array}{l}\text { Coated cast iron ( } 316 \mathrm{~L} \\
\text { coating) }\end{array}$ & 30.584 & 4.580 & 26.098 & 35.611 \\
\hline \multicolumn{5}{|c|}{ Effect of coated surface (reference state: stress relief annealing) } \\
\hline HVOF coated surface & $\begin{array}{c}\text { Decreases with } \\
54.89 \% \text { or } \\
2.216 \text { times }\end{array}$ & $\begin{array}{c}\text { Decreases } \\
\text { with } 67.98 \% \\
\text { or } 3.123 \text { times }\end{array}$ & $\begin{array}{c}\text { Decreases with } \\
64.73 \% \text { or } \\
2.835 \text { times }\end{array}$ & $\begin{array}{c}\text { Decreases with } \\
64.77 \% \text { or } \\
2.838 \text { times }\end{array}$ \\
\hline
\end{tabular}

which are extenting toward the core of the cast iron. The coating 316L (fig. 11b) shows a smaller wear penetration

because of the cavitation attack. One can say that the coating microstructure is favourable to resist by the cavitation wear by cracking or chipping.

\section{Roughness measurements}

Figure 12 presents three significant images of the surface roughness profiles for $316 \mathrm{~L}$ coating after cavitation testing for 165 min. The values of the Ra, Rz and Rt parameters were determined using a Mitutoyo apparatus.

The presented data were recorded in 12-16 areas, arbitrarily chosen, on the eroded surface, from the periphery to the central area. The smallest values occurred in the zones near the centre of the cavity, and the higher values
Fig.12. HVOF sprayed 316L coating: profile and roughness values $R_{a^{\prime}}, R_{z^{\prime}}, R_{t}$ measured on the three directions
Table 1

COMPARATIVE ANALYSIS OF PARAMETERS ROUGHNESSAND EROSION DEPTH, MDE ${ }_{(165 \text { minutes })}$ are registered to the periphery. Profile shapes are justified by the fine microstructure and the hardness of the surface layer exposed to the cavitation phenomenon.

The data from table 1 show the positive effect of the HVOF thermal spraying technique using austenitic stainless steel pow ders on the decrease of both erosion penetration depth and the parameters which characterize the samples surface. It is noted that, in comparison with uncoated surface, there is a reduction of the MDE value at the end of the cavitation test of approx. 2.2 times and approx. 2.8 - 3 times of the roughness parameters.

The histogram from figure 13 highlights that surface roughness can be an important indicator in evaluation the cavitation resistance of metallic materials; the proposed coating process using 316 L stainless steel pow der provides 


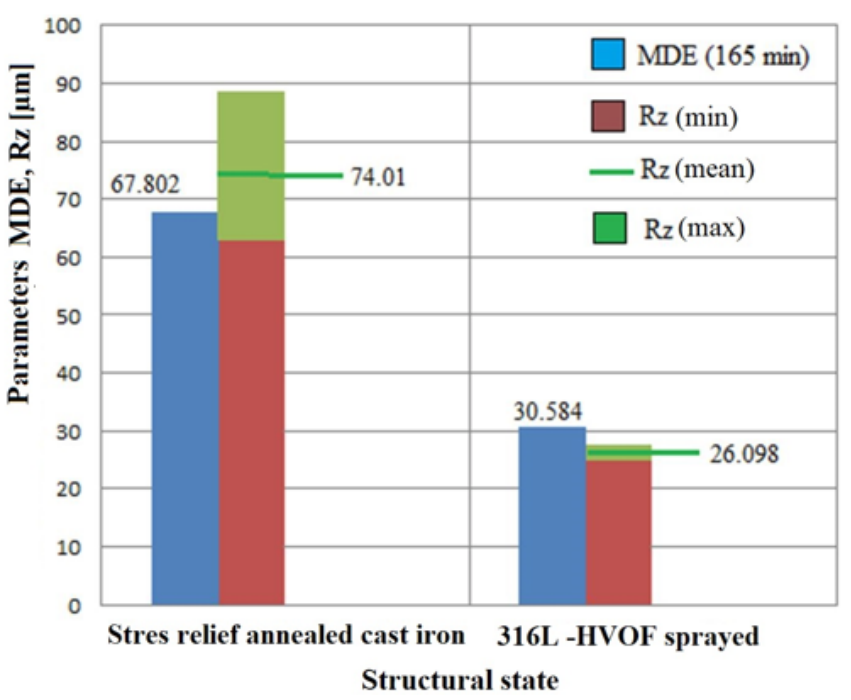

Fig.13. Effect of the structural state on $R z$ and $M E_{(165 \text { minute })}$ parameters

a substantial improvement in the durability of engineering components which operate in cavitation environments.

Electrochemical corrosion tests

The corrosion behaviour of the specimens was evaluated by electrochemical tests using a 3.5wt. \% NaClaqueous solution. Before measurements the surface of the substrate and of the $316 \mathrm{~L}$ coating was grinded to a surface roughness of 1.5 microns. The exposed surface into the corrosion

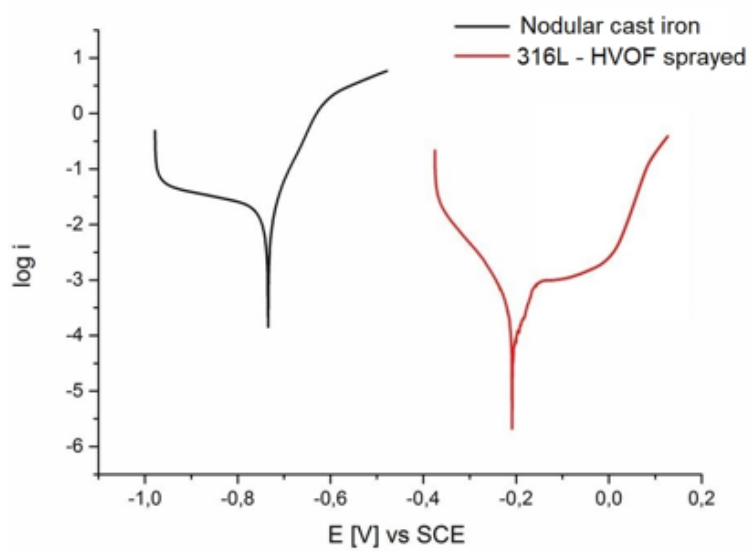

Fig.14. Potentiodynamic polarization curves of the samples tested in $3.5 \% \mathrm{NaCl}$ solution

Table 2

RESULTS OF THE POTENTIODYNAMIC CORROSION TEST

\begin{tabular}{|l|l|l|l|}
\hline Material & $\mathbf{E}, \mathbf{m V}$ & $\overline{\mathbf{i}}_{\text {corr }}, \boldsymbol{\mu A} / \mathbf{c m}^{2}$ & $\mathbf{v}_{\text {corr }}, \mathbf{m m} /$ year \\
\hline Nodular cast iron & -735.633 & 19.752 & 0.232 \\
\hline 316L-HVOF sprayed & -205.597 & 0.494 & 0.0058 \\
\hline
\end{tabular}

media was $1 \mathrm{~cm} 2$. The polarisation curves of the tested samples are presented in figure 14 and the corrosion parameters are listed in table 2 .

Comparing the curves from figure 14 and analysing the electrochemical data from table 2 one can observed that the HVOF coating of nodular cast iron with 316L stainless steel had led to better chemical properties. The corrosion current values were shifted from $19.752 \mu \mathrm{A} / \mathrm{cm}^{2}$ (uncoated cast iron) to $0.494 \mu \mathrm{A} / \mathrm{cm} 2$ (coated cast iron) which means an improvement of the corrosion resistance. Also the corrosion rate of coated castiron was significantly reduced with a factor of 40 in comparison with the uncoated cast iron.

The worse corrosion properties of the uncoated nodular cast iron can be attributed to the heterogeneous microstructure of the metallic matrix and of the graphite inclusions.

\section{Conclusions}

AISI 316L stainless steel coatings were successfully deposited onto the surface of nodular cast iron by HVOF spraying technique in order to improve their cavitation and corrosion resistance.

X-ray diffraction analysis have shown that for the used HVOF deposition conditions, the selected powder material consists of approx. $94 \%$ austenite and $6 \%$ ferrite $\delta$, and the deposited layer of approx. $91 \%$ austenite and $9 \%$ ferrite $\delta$.

The experimental results showed good cavitation properties of coated (316L pow der) and uncoated (stress relief annealed) cast iron. Compared to the structural state specific to the stress relief annealing heat treatment, the proposed coating process, using $316 \mathrm{~L}$ powder, favours an increase in cavitation resistance of approx. 2.7 times.

The investigations performed using optical and scanning electron microscopy revealed that the HVOF coated surfaces present a uniform material degradation and less cavitation attack penetration, and the eroded area shows no pinches, micro cracks or deep craters.

The surface profilograms of the coated surfaces, after 165 cavitation time, show that the values of the Ra, Rz and Rt parameters are lower than approx. 2.8 - 3 times compared to those characteristic to the reference state of the material (stress relief annealed cast iron).

The corrosion behaviour has revealed also better properties of the coated cast iron, the corrosion rate being reduced from $0.232 \mathrm{~mm} /$ year (nodular cast iron) to 0.0058 $\mathrm{mm} /$ year (316L coating).

It can be concluded that the deposition of $316 \mathrm{~L}$ stainless steel coatings using HVOF method can produce dense coatings with enhanced characteristics in terms of corrosion and cavitation resistance.

\section{References}

1. PULLAN, T.T., Spheroidal graphite cast iron property enhancement by heat treatment, Int. J. Mater. Res., 107(9), 2016, pp. 807-814.

2. ORLOWICZ, A.W., MROZ, M., TUPAJ, M., TRYTEK, A., JACEK, M., RADON, M., Cavitation Erosion of Nodular Cast Iron Microstructural Effects, Arch. of Foundry Engin., 17(4), 2017, pp. 119-122.

3. AL-HASHEM, A., ABDULLAH, A., RIAD W.T., Cavitation corrosion of nodular cast iron (NCl) in seawater,Mater. Charact., 47(5), 2001, pp. 383 - 388.

4. VASKO, A., HURTALOVA, L., UHRICIK, M., TILLOVA, E., Fatigue of nodular cast iron at high frequency loading,Materialwiss. Werkstofftech., 47(5-6), 2016, pp. 436-443.

5.HUG, E., KELLER, C., FAVERGEON, J., DAW K., Application of the Monkman -Grant law to the creep fracture of nodular cast irons with various matrix compositions and structures, Mater. Sci. and Eng.: A, 518(1-2), 2009, pp. 65-75.

6. KURYLO, P., Possibility of plastic processing of spheroidal cast iron, Procedia Eng., 48, 2012, pp. 326 - 331.

7. BENA T., MITELEA I., BORDEASU I., UTU I.D., CRACIUNESCU C.M., The quenching - tempering heat treatment and cavitation resistance of nodular cast iron with ferrite-pearlite microstructure, Metal 2017: 26th International Conference on Metallurgy and Materials, 2017, pp. 731-736 
8. ANTON, A. A., MUNTEAN, S., SUSAN-RESIGA, R. F., SWIRL2D: AN INTERFACE TRACKING ALGORITHM FOR COMPUTING THE TWODIMENSIONAL SWIRLING FLOWS WITH STAGNANT REGION, Proceedings of ihe Romanian Academy Series A-Mathematics Physics Technical Sciences Information Science, Volume 17, Issue 4, 2016, pp. 366-373

9.ANTON, A. A., CRETU, V., RUPRECHT, A., MUNTEAN, S., TRAFFIC REPLAY COMPRESSION (TRC): A HIGHLY EFFICIENT METHOD FOR HANDLING PARALLEL NUMERICAL SIMULATION DATA, Proceedings of ihe Romanian Academy Series A-Mathematics Physics Technical Sciences Information Science, Volume 14, Issue 4, 2013, pp. 385-392 10. MITELEA, I., BORDEASU, I., MICU, L.M., CRACIUNESCU, C.M., Microstructure and Cavitation Erosion Resistance of the X2CrNiMoN225-3 Duplex Stainless Steel Subjected to Laser Nitriding, Rev. Chim. (Bucharest), 68, no. 12, 2017, p. 2992-2996.

11. HOU, G.L., ZHAO, X.Q., ZHOU, H.D., LU, J.J., AN, Y.L., CHEN, J.M., YANG, J., Cavitation erosion of several oxy-fuel sprayed coatings tested in deionized water and artificial seawater, Wear, 311, 2014, p. 81-92. 12. BIEHLER, J., HOCHE, H., OECHSNER, M., KAESTNER, P., BUNK, $K ., B R A U E R, G$., Influence of the microstructure on the corrosion resistance of plasma-nitrided austenitic stainless steel 304L and 316L,Materialwiss. Werkstofftech., 45(10), 2014, pp. 930-946.

13. SUN, B., FUKANUMA, H., OHNO, N., Study on stainless steel 316L coatings sprayed by a novel high pressure HVOF, Surf. Coat. Technol., 239, 2014, pp. 58-64.

14.ASHJA, M., VERDIAN, M.M., Al-Cu-Fe coatings manufactured by the flame spraying process, Mater. Manuf. Process., 32(4), 2017, pp. 383388.
15. SINGH, H., KHOSLA, H., SIDHU, T.S., KALSI, S.B.S, KARTHIKEYAN, J., Characteristic study of N07718 superalloy surface prepared by cold spray, Mater. Manuf. Process., 33(2), 2018, pp. 140-148.

16. DING, X., CHENG, X.D., YUAN, C.Q., SHI, J., DING, Z. X., Structure of Micro-nano WC-10C04Cr Coating and Cavitation Erosion Resistance in $\mathrm{NaCl}$ Solution, Chin. J. Mech. Eng., 30(5), 2017, pp. 1239-1247.

17. *** Standard test method for cavitation erosion using vibratory apparatus ASTM G32-2010

18. MITELEA, I., MICU, L. M., BORDEASU, I., CRACIUNESCU, C. M., Cavitation Erosion of Sensitized UNS S31803 Duplex Stainless Steels, J OURNAL OF MATERIALS ENGINEERING AND PERFORMANCE, 25(5), 2016, pp.1939-1944

19 KRAWCZYNSKA, A.T., LEWANDOWSKA, M., FRY, A.T., Microstructural characterization and residual stress distribution in a nanostructured austenitic stainless steel, Internat. J. Mater. Res., 109(9), 2018, pp. 837-843.

20 XIONG, Y., HE, T.T. LU, Y., REN, F.Z., VOLINSKY, A.A., CAO, W., Tensile Deformation Temperature Impact on Microstructure and Mechanical Properties of AISI 316LN Austenitic Stainless Steel, J. Mater. Eng. Perform. 27(3), 2018, pp. 1232-1240.

21 MITELEA, I., BENA, T., BORDEASU, I., CRACIUNESCU, C.M., Relationships Between Microstructure, Roughness Parameters and Ultrasonic Cavitation Erosion Behaviour of Nodular Cast Iron, ENGJ S-400-15, Rev. Chim (Bucharest), 69, no. 3, 2018, p. 612-617.

22 BORDEASU, I., MITELEA, I., SALCIANU, L., CRACIUNESCU, C. M., Cavitation Erosion Mechanisms of Solution Treated X5CrNi18-10 Stainless Steels, JOURNAL OF TRIBOLOGY-TRANSACTIONS OF THE ASME, Volume: 138, Issue: 3, 2016, Article Number: 031102, DOI: $10.1115 / 1.4032489$.

Manuscript received: 3.12 .2018 